\title{
Inheritance of chlorpyrifos resistance in Culex pipiens L. (diptera: culicidae) and estimation of the number of genes involved
}

\author{
Michel Raymond*†, Nicole Pasteur*, \\ and George P. Georghiou $\dagger$
}

\begin{abstract}
* Laboratoire de Génétique, Institut des Sciences de l'Evolution (UA 327), Université de Montpellier II, 34060 Montpellier, France.

$\dagger$ Division of Toxicology and Physiology, Department of Entomology, University of California, Riverside, CA 92521, U.S.A.
\end{abstract}

The inheritance of chlorpyrifos resistance has been studied in a strain (MSE) derived from larvae collected in southern France in 1979, using two susceptible strains (S-LAB and YPL). All F1 offspring displayed straight dosage-mortality (ldp) lines confirming that the susceptible and the resistant strains were homozygous for the genes involved. All backcross $l d p$ lines differed significantly from those expected if resistance had been monofactorial and were straight regression lines. Based on the crosses involving the $S$ - $L A B$ strain, the number of additive and independent genes contributing to chlorpyrifos resistance was estimated to be at least 2 and perhaps more. The evolution of chlorpyrifos resistance in natural populations in southern France is discussed in the light of these findings.

\section{INTRODUCTION}

The presence of chlorpyrifos resistance was first detected in southern France in 1972 (Sinègre, Jullien and Crespo, 1976). Research conducted in 1975 indicated that this resistance was due to the Est-3A gene coding increased esterase detoxification (Pasteur, 1977; Pasteur, Iseki and Georghiou, 1981). In 1979, a significant increase in the level of chlorpyrifos resistance was noted (Pasteur, Sinègre and Gabinaud, 1981) and a strain with a high resistance was isolated and made free of the Est-3A gene (Raymond et al., 1985b). In the present investigation, we examine the inheritance of chlorpyrifos resistance in this strain (MSE) and we estimate the number and identity of independent and additive genes contributing to resistance.

\section{MATERIALS AND METHODS}

The MSE strain has been maintained for more than 1 year free of insecticide exposure and its resistance has remained remarkably constant. $M S E$ mosquitoes were mass crossed with two susceptible strains, $S-L A B$ (Georghiou, Metcalf and Glidden,
1966) and YPL (Guptavanij and Barr, 1979). The $F 1$ offspring of these crosses, i.e., (noting the female parent first)

$$
\begin{aligned}
\text { I. } & S-L A B \times M S E, \\
\text { II. } & M S E \times S-L A B \text { and } \\
\text { III. } & Y P L \times M S E,
\end{aligned}
$$

were then backcrossed to their respective susceptible or resistant parents, or were inbred, viz.

$$
\begin{aligned}
\text { IV. } & Y P L \times(Y P L \times M S E), \\
\text { V. } & S-L A B \times(S-L A B \times M S E), \\
\text { VI. } & (S-L A B \times M S E) \times M S E \text { and } \\
\text { VII. } & (S-L A B \times M S E) \\
& \times(S-L A B \times M S E) .
\end{aligned}
$$

Bioassays were conducted on fourth-instar larvae in disposable waxed cups holding $100 \mathrm{ml}$ of tap water containing different concentrations of chlorpyrifos. In each test, sets of 20 larvae were exposed to the insecticide during $24 \mathrm{hrs}$. The action of two synergists, DEF ( $S, S, S$, tributylphosphorotrithioate) an inhibitor of esterases and glutathione-S-transferases, and $\mathrm{Pb}$ (piperonyl butoxide) an inhibitor of oxidases, was investigated by exposing larvae to $0.5 \mathrm{mg} / \mathrm{L} D E F$ or $5 \mathrm{mg} / \mathrm{L} \mathrm{Pb} 4 \mathrm{hrs}$ prior to the addition of chlorpyrifos. To standardise the bioassays, the solvent 
(absolute-ethanol) concentration was systematically adjusted to 1 per cent. Selections were conducted on the backcrosses under the same experimental conditions as for the bioassays. Offspring from the backcrosses to the $S-L A B$ strain (cross V or V-1) was treated with $0.05 \mathrm{mg} / \mathrm{L}$ chlorpyrifos and offspring from the backcrosses to the $M S E$ strain (cross VI or VI-1) was treated with $0.4 \mathrm{mg} / \mathrm{L}$ chlorpyrifos. Larvae surviving after 24 hours were reared under insecticide free conditions and their adults were mass-crossed to the appropriate strain. In all, five successive backcrosses were made to $S-L A B$ and two to $M S E$, thus,

\section{V-1. $S-L A B \times(S-L A B \times M S E)$ \\ V-2. $S-L A B \times \mathrm{V}-1$ selected \\ V-3. $S-L A B \times V-2$ selected \\ V-4. $S-L A B \times V-3$ selected \\ V-5. $S-L A B \times \mathrm{V}-4$ selected \\ VI-1. $(S-L A B \times M S E) \times M S E$ \\ VI-2. VI-1 selected $\times M S E$}

The results of bioassays were analysed on a IBM-PC using the probit analysis program of Raymond (1985). The classical probit analysis method of Finney (1971) does not provide an estimate of the variance of the reciprocal of the slope. When this parameter was needed, randomization tests (Sokal and Rohlf, 1981) were carried out.

The dominance level $(D)$ of the resistance in the $F 1 s$ was estimated using the index of Stone (1968). This parameter varies linearly from -1 , indicating complete recessivity, to +1 , indicating complete dominance, with 0 corresponding to perfect codominance. The confidence limits of $D$ were calculated according to Misra (1968).

\section{RESULTS}

\section{Resistance characteristics in the parental strains and their F1 offspring}

The parental strains $M S E, S-L A B$, and $Y P L$ were characterised by straight $l d p$ lines when bioassayed with chlorpyrifos (fig. 1) indicating that each strain was homogeneous with respect to its susceptibility characteristics. The two reciprocal $F 1$ crosses between $M S E$ and $S$ - $L A B$ (crosses I and II) as well as the $F 1$ between $Y P L$ and MSE (cross III) were also characterised by straight $l d p$ lines $(P>$ $0.3,0.2$ and 0.09 , respectively) confirming that $M S E, Y P L$ and $S .-L A B$ are homozygous for the resistance (or susceptibility) genes they possessed.

The characteristics of the $l d p$ lines of the parental strains and of their $F 1$ offspring are given in table 1 . These allow calculation of the degree of dominance of resistance in each $F 1$ according to the index used by Stone (1968). Approximately the same dominance values were observed in the $F 1 s$ between MSE and $S-L A B$ or YPL $(0.22 \pm$ $0 \cdot 01,0 \cdot 26 \pm 0.01$ and $0 \cdot 25 \pm 0.01$ in crosses I, II and III, respectively).

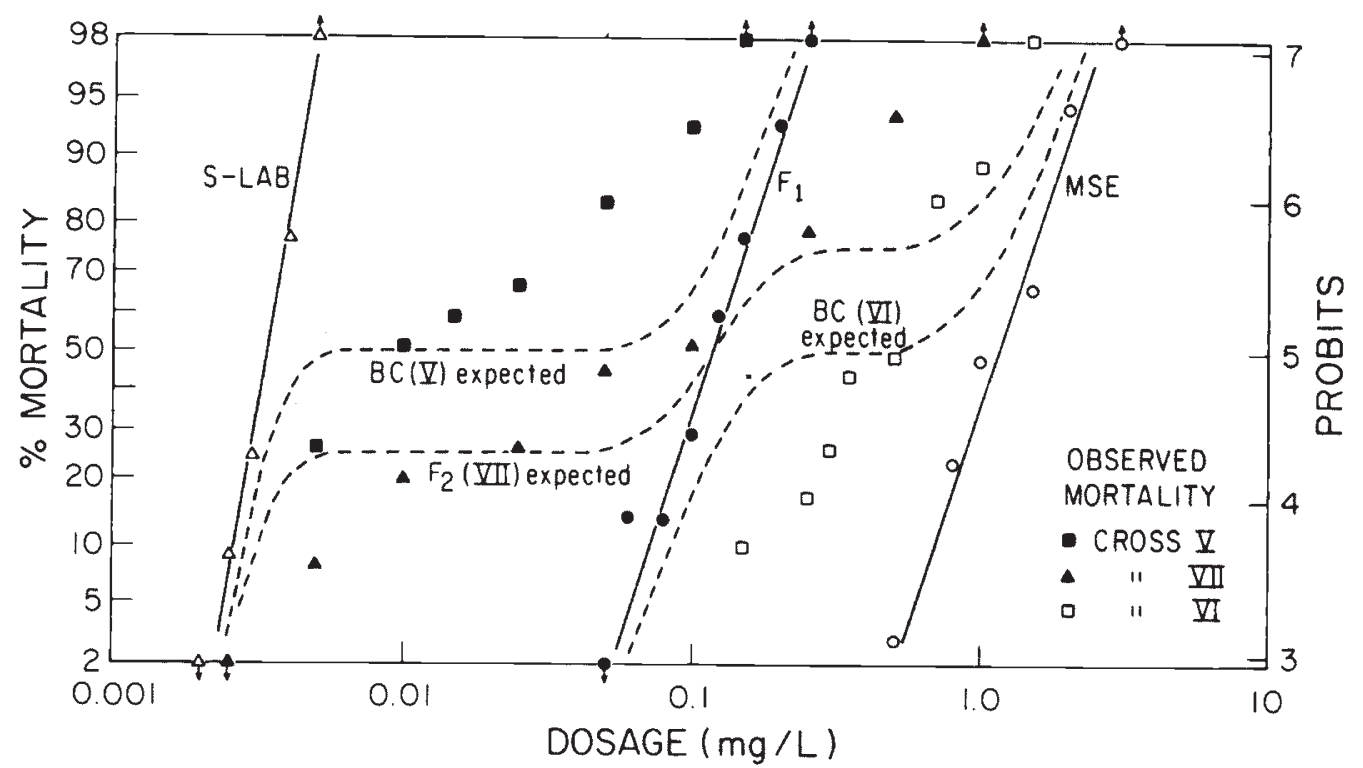

Figure $1 L p d$ lines for chlorpyrifos obtained against strains $S$-LAB and $M S E$, their $F 1, F 2$ and backcross (V, VI) offspring. Broken lines indicate the expected mortalities in case of monofactoriality. 
Table 1 Characteristics of dose-mortality regression lines in larvae of the various strains and crosses

\begin{tabular}{|c|c|c|c|c|c|}
\hline $\begin{array}{l}\text { Strain } \\
\text { or Cross }\end{array}$ & $\begin{array}{l}\text { LC50 (95\% cf. int. }) \\
\left(\mathrm{mg} / \mathrm{L} \times 10^{-2}\right)\end{array}$ & Slope (SE) & DF & $\mathrm{Chi}^{2}$ & $H^{*}$ \\
\hline$M S E$ & $1075(1017-1142)$ & $5.42(0.43)$ & 4 & $7 \cdot 72$ & 1 \\
\hline$S \cdot L A B$ & $3 \cdot 34(3 \cdot 22-3 \cdot 46)$ & $11.6(0.86)$ & 3 & $5 \cdot 72$ & 1 \\
\hline$Y P L$ & $5 \cdot 53(5 \cdot 29-5 \cdot 77)$ & $7 \cdot 50(0.64)$ & 3 & $2 \cdot 00$ & 1 \\
\hline I & $114(110-118)$ & $5.97(0.33)$ & 5 & $5 \cdot 95$ & 1 \\
\hline II & $128(123-135)$ & $6 \cdot 29(0.40)$ & 4 & $6 \cdot 05$ & 1 \\
\hline III & $143(134-152)$ & $4.46(0.35)$ & 3 & $6 \cdot 31$ & 1 \\
\hline IV & $12 \cdot 8(9.97-15 \cdot 7)$ & $1 \cdot 57(0 \cdot 16)$ & 5 & $5 \cdot 82$ & 1 \\
\hline V-1 & $9 \cdot 91(7 \cdot 89-1 \cdot 20)$ & $1.48(0 \cdot 13)$ & 5 & $4 \cdot 67$ & 1 \\
\hline V-2 & $11(9 \cdot 10-13 \cdot 0)$ & $1 \cdot 50(0 \cdot 14)$ & 4 & $1 \cdot 52$ & 1 \\
\hline V-3 & $7 \cdot 15(4 \cdot 97-9 \cdot 29)$ & $1 \cdot 17(0 \cdot 14)$ & 4 & $3 \cdot 61$ & 1 \\
\hline V-4 & $8 \cdot 49(5 \cdot 92-11 \cdot 0)$ & $1.08(0.13)$ & 4 & $6 \cdot 52$ & 1 \\
\hline V.5 & $12 \cdot 5(9 \cdot 83-15 \cdot 4)$ & $1 \cdot 23(0 \cdot 13)$ & 4 & $5 \cdot 46$ & 1 \\
\hline VI-1 & $415(338-510)$ & $3.06(0.40)$ & 6 & $21 \cdot 1$ & 4.91 \\
\hline VI-2 & $354(302-415)$ & $2 \cdot 36(0 \cdot 23)$ & 7 & $15 \cdot 0$ & $2 \cdot 15$ \\
\hline VII & $59 \cdot 3(42 \cdot 4-82.9)$ & $1.47(0.13)$ & 7 & $18 \cdot 7$ & 2.67 \\
\hline
\end{tabular}

* Heterogeneity factor (Finney, 1971).

Resistance characteristics in larvae of the backcrosses and F2

When resistance is monofactorial, the mortality curves expected in the backcross and $F 2$ progenies can be calculated from the mortality lines of the parental strains and their $F 1$. The mortality lines observed in all backcrosses and $F 2$ tested in this study differ significantly $(P<0.001)$ from those that would be expected if resistance in the $M S E$ strain is monofactorial (fig. 1 shows results). In all the backcrosses (crosses IV to VII), mortality lines were straight (fig. 2 and table 1). These results indicate that resistance in the $M S E$ strain is due to more than one gene. This conclusion is in agreement with previous studies that showed the presence in the MSE strain of an insensitive acetylcholinesterase (AChE) coded by the Ace R allele, and a modified oxidative detoxification (Raymond et al., 1985c, 1986).

Five successive backcrosses to $S-L A B$ (crosses $\mathrm{V}-1$ to $\mathrm{V}-5)$ were obtained from the $F 1(S-L A B \times$ $M S E)$ after exposing the larvae of each backcross to $0.05 \mathrm{mg} / \mathrm{L}$ chlorpyrifos (a dose that is lethal to

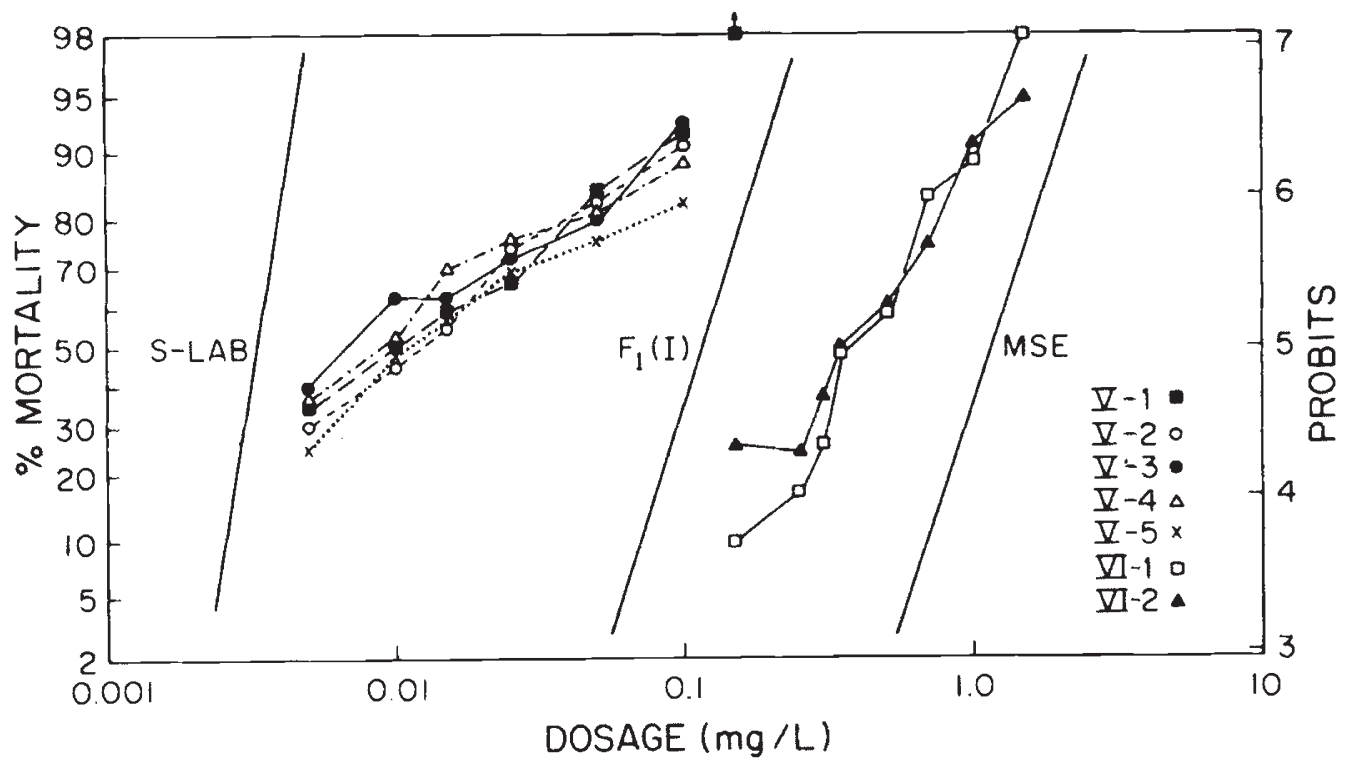

Figure $2 L p d$ lines obtained with chlorpyrifos against offspring of the repetitive backcrosses (crosses V-1 to V-5; VI-1 and VI-2). See text for explanations. 
Table 2 Maximum number of genes $(n)$ involved in chlorpyrifos resistance deduced from the mortality of various backcrosses treated with chlorpyrifos (see text for explanation)

\begin{tabular}{llllll}
\hline Cross & $\begin{array}{l}\text { Dose } \\
(\mathrm{mg} / \mathrm{L})\end{array}$ & Treated & $\begin{array}{c}\text { Number } \\
\text { Killed }\end{array}$ & $\begin{array}{l}\text { Mortality } \\
( \pm \mathrm{SE})\end{array}$ & $n$ (Range) \\
\hline V-1 & $0 \cdot 05$ & 580 & 437 & $75 \cdot 3( \pm 3 \cdot 5)$ & $2 \cdot 0(1 \cdot 8-2 \cdot 2)$ \\
V-2 & $0 \cdot 05$ & 580 & 490 & $84 \cdot 5( \pm 2 \cdot 9)$ & $2 \cdot 7(2 \cdot 4-3 \cdot 0)$ \\
V-3 & $0 \cdot 05$ & 660 & 551 & $83 \cdot 5( \pm 2 \cdot 8)$ & $2 \cdot 6(2 \cdot 4-2 \cdot 9)$ \\
V-4 & $0 \cdot 05$ & 820 & 675 & $82 \cdot 3( \pm 2 \cdot 6)$ & $2 \cdot 5(2 \cdot 3-2 \cdot 7)$ \\
V-5 & $0 \cdot 05$ & 580 & 491 & $84 \cdot 7( \pm 2 \cdot 9)$ & $2 \cdot 7(2 \cdot 5-3 \cdot 0)$ \\
VI-1 & $0 \cdot 4$ & 440 & 330 & $75 \cdot 0( \pm 4 \cdot 0)$ & $2 \cdot 0(1 \cdot 8-2 \cdot 3)$ \\
\hline
\end{tabular}

all susceptible phenotypes but does not affect significantly the $F 1$ ). The mortalities obtained increased slightly between V-1 and V-2 $(P<0.05)$ and remained stable thereafter (table 2). The mortality curves (fig. 3) did not differ significantly $(P>0.3)$ from one backcross to the next showing that the survivors of each backcross were genetically identical among themselves and with the $F 1$ larvae. The genetic similarity of V-5 survivors with $F 1$ larvae was verified with respect to the Ace gene using the Raymond et al. (1985a) technique: all (43) larvae examined were Ace R/AceS heterozygous as were the $F 1$ larvae. In addition, V-5 larvae were exposed to various chlorpyrifos doses in the presence of the synergists $D E F$ or $P b$. Both compounds modify the mortality lines (fig. 3) but whereas this line remained straight $(P>0.45)$ with $D E F$, it clearly displayed a plateau at the 50 per cent mortality level with $\mathrm{Pb}$. Thus, when oxidases are inhibited, the segregation of a major resistance gene (most probably the Ace gene) becomes evident. Oxidases are, therefore, significantly con- tributing to the resistance observed in the $M S E$ strain.

Two successive backcrosses to MSE (crosses VI-1 and VI-2) were conducted using the $F 1$ ( $S$ $L A B \times M S E$ ) with concurrent selection at $0.4 \mathrm{mg} / \mathrm{L}$ chlorpyrifos, a dose that does not affect $M S E$ larvae significantly but is lethal to $F 1$. The mortality curves of VI-1 and VI-2 did not differ significantly $(P>0 \cdot 1)$ from one another (fig. 2$)$. VI-1 survivors were, therefore, genetically identical to the larvae of the $M S E$ strain, as far as resistance genes were concerned.

\section{Estimation of the number of genes involved in chlorpyrifos resistance in the MSE strain}

The number of independent genes with additive effects that contribute to the expression of a quantitative trait (such as chlorpyrifos resistance) can be estimated from (a) the mortality data obtained in successive selected backcrosses or (b) the means and the variances of the resistance character in the

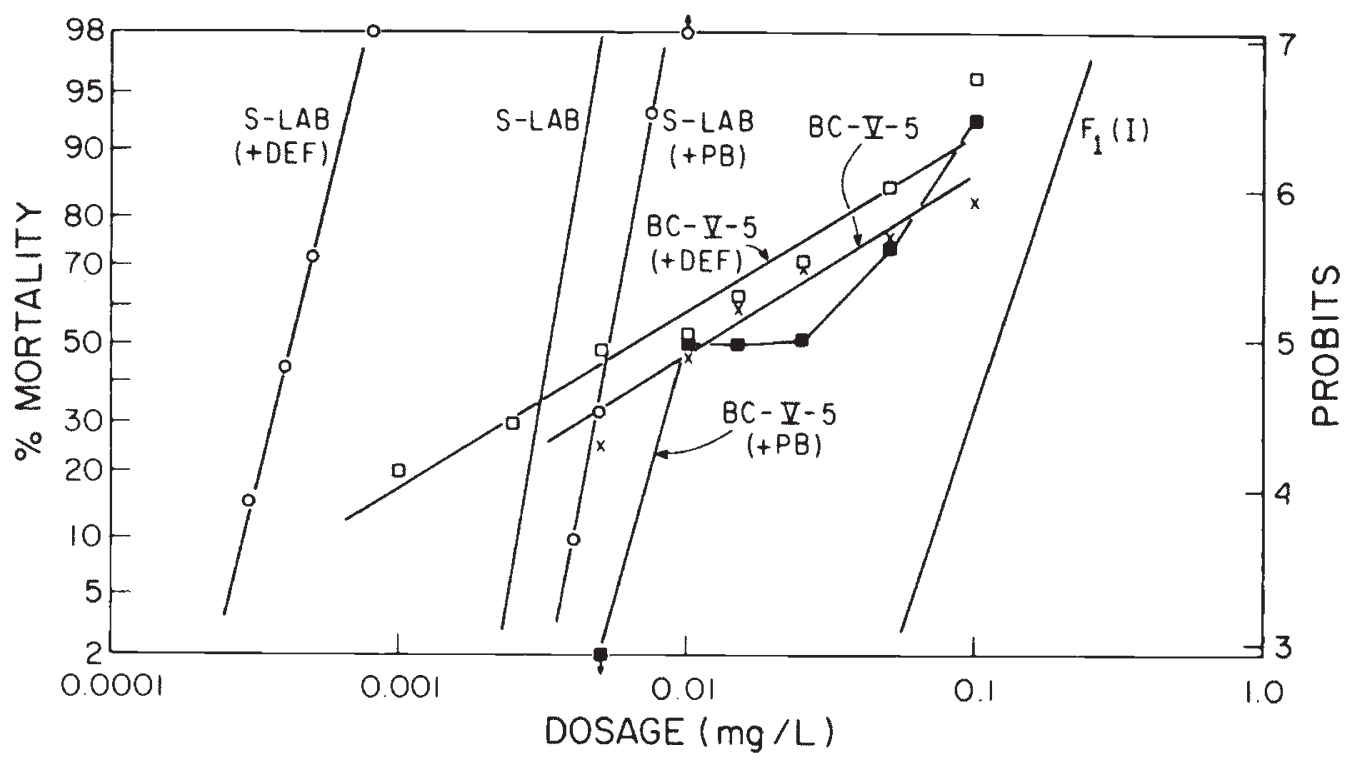

Figure 3 Synergism of the 5th repetitive backcross (V-5) and the $S-L A B$ strain with $P b$ and $D E F$. 
parental strains and in their $F 2$ or backcross offspring by applying Wright's formula (see below).

Thus, using the survivorship data of the backcrosses to the $S-L A B$ parent (crosses V-1 to V-5), the proportion of larvae similar to the $F 1$ (i.e., surviving $0.05 \mathrm{mg} / \mathrm{L}$ chlorpyrifos) will be equal to $(1 / 2)^{n}$ if $n$ independent genes control resistance in the $M S E$ strain. The number of resistance genes will then be

$$
n=\log (\% \text { survivors }) / \log (1 / 2) .
$$

Considering the mortalities observed in the V-1 to V-5 backcrosses to the $S-L A B$ strain (table 2), it was calculated that 2 or 3 genes account for the resistance. When the backcrosses to the MSE parent are considered by the same method (cross VI-1 and VI-2), an estimate of two genes is obtained.

Wright's formula (in Castle, 1921) giving the number of independent genes with additive effects contributing to the expression of a quantitative character is

$$
n=\left(\mu_{2}-\mu_{1}\right)^{2} /\left(8 \times \sigma^{2}\right)
$$

where $\mu_{1}$ and $\mu_{2}$ are the means of the character in the two parental strains, and $\sigma^{2}$ is the genetic variance of the character observed in the $F 2$ or backcrosses. With resistance characters the mean of the distribution corresponds to the decimal logarithm of the LC50 and its variance to the reciprocal of the slope of the ldp line (table 3 ). Estimates of the genetic variance were made using various formulae provided by Lande (1981) depending on the cross considered. Thus, the minimum number of genes controlling chlorpyrifos resistance in the $M S E$ strain was estimated to be between 1 and 2 (table 4). As noted by Lande (1981) such values may underestimate the actual number of genes if the latter are linked and/or have no additive effects.
Table 3 Means $(\mu=\log (\mathrm{LC} 50))$ and slope reciprocal $(1 / b)$ of the resistance character in the crosses involving $S-L A B$ and MSE strains. Variances in parenthesis

\begin{tabular}{lllll}
\hline $\begin{array}{l}\text { Strain } \\
\text { or Cross }\end{array}$ & $\mu$ & $\begin{array}{l}(\operatorname{Var}(\mu) \\
\left.\times 10^{-5}\right)\end{array}$ & $1 / b$ & $\begin{array}{l}(\operatorname{Var}(1 / b) \\
\left.\times 10^{-4}\right)\end{array}$ \\
\hline$S-L A B$ & -2.48 & $(5.95)$ & 0.086 & $(1.65)$ \\
$M S E$ & 0.0314 & $(15.9)$ & 0.185 & $(12.8)$ \\
I & -0.945 & $(7.91)$ & 0.168 & $(14.6)$ \\
V & -2.00 & $(97.8)$ & 0.674 & $(309)$ \\
VI & -0.382 & $(132)$ & 0.326 & $(11.2)$ \\
VII & -1.23 & $(375)$ & 0.681 & $(73.0)$ \\
\hline
\end{tabular}

\section{DISCUSSION}

The inheritance of resistance to chlorpyrifos in the MSE strain, was found to be multifactorial: the mortalities observed in all backcross and $F 2$ generations differ significantly from those expected when resistance is due to a single gene. From the crosses between $M S E$ and $S-L A B$, the number of genes controlling chlorpyrifos resistance was estimated by two independent methods to be between 2 and 3 . In both cases, these values may be an underestimation if the resistance genes are linked and/or their effects are non-additive.

The presence of a plateau at 50 per cent mortality in the $l d p$ line of cross V-5 obtained with chlorpyrifos $+\mathrm{Pb}$ suggests that a major resistance gene is segregating when the $M F O$ system is suppressed. Since the survivors of this cross possessed the Ace $\mathrm{R}$ allele, these results strongly support the view that resistance in $M S E$ is due primarily to reduced sensitivity of acetylcholinesterase and a modified MFO. The results obtained also suggest that other genetic effects may be involved in chlorpyrifos resistance. This is indicated in the crosses to the $S-L A B$ through the use of $P b$, because the curve $B C-V-5$ in fig. 3 differs slightly from the expected curve for monofactorial control.

Intensive chemical control of Culex pipiens as practised in southern France (Sinègre, Jullien and

Table 4 Estimation of the number of genes contributing to chlorpyrifos resistance using Lande's (1981) method. Each calculation (1-4) is based on a different estimation of the genetic variance

Estimation of the genetic variance $\left(\sigma^{2}\right)$

Estimation of $n$

$\pm \mathrm{SE}$

(1) $\sigma^{2}=\sigma_{\mathrm{y} 11}^{2}-\sigma_{1}^{2}$

$1 \cdot 5 \pm 0 \cdot 2$

(2) $\sigma^{2}=\sigma_{\text {VII }}^{2}-\left(\frac{1}{2} \cdot \sigma_{1}^{2}+\frac{1}{4} \cdot \sigma_{S-L A B}^{2}+\frac{1}{4} \cdot \sigma_{M S E}^{2}\right)$

(3) $\sigma^{2}=2 \sigma_{\mathrm{VII}}^{2}-\sigma_{\mathrm{V}}^{2}-\sigma_{\mathrm{VI}}^{2}$

$1 \cdot 5 \pm 0.5$

(4) $\sigma^{2}=\sigma_{\mathrm{V}}^{2}+\sigma_{\mathrm{V}}^{2}-\left(\sigma_{1}^{2}+\frac{1}{2} \cdot \sigma_{S-L A B}^{2}+\frac{1}{2} \cdot \sigma_{M S E}^{2}\right)$

$1 \cdot 1 \pm 0.6$

* Standard error exceeds estimate. 
Crespo, 1976) represents undoubtedly a dramatic change in the environment of mosquito populations. This study of the resistance genes found in the MSE strain collected in 1979 illustrates the evoluticnary changes occurring in such populations. In 1971 all the populations examined were susceptible, resistance having first been detected in one locality (Lunel-Viel) in 1972 (Sinègre, Jullien and Crespo, 1976). By 1974-1975 resistance had increased rapidly, being found over the entire treated zone and was strictly associated with a highly active detoxifying esterase encoded by the Est-3A gene. No mosquito in any of the populations sampled during 1974 and 1975 could survive chlorpyrifos doses that were lethal to the resistant reference strain S54 which is homozygous for the Est-3A gene (Pasteur 1977, Pasteur and Sinègre 1978). Thus, Est-3A was the first gene selected in natural populations. However, during 1978-1979 although the correlation between the presence of Est-3A and chlorpyrifos resistance continued to be good, individual mosquitoes in some populations were found to tolerate doses that were lethal to S54 larvae (Pasteur, Sinègre and Gabinaud, $1981)$. From the present study of the MSE strain (which lacks the Est-3A gene), it is evident that the enhanced survival was due to the presence of two or possibly three newly selected resistance genes.

Thus, chlorpyrifos resistance in southern France while initially monofactorial, subsequently became multifactorial. Such a change is not based only on selection of modifiers, since at least one of the subsequently selected genes, Ace R, provides by itself higher resistance than is conferred by the Est-3A gene. Apparently, the shift from monofactoriality to multifactoriality of chlorpyrifos resistance has a more complicated basis than the simple selection of modifiers.

Acknowledgments This research was supported by the University of California Mosquito Research Program, grants from NSF (N. 8413822) and CNRS under the US-France Collaborative Science Program, INSERM (Contrat de Recherche Externe $N^{\circ} 841019$ ), PIREN-CNRS (AIP Ecotoxicologie) and by a Paul Valery fellowship from the Ministère des Relations Extérieures de France to M.R.

\section{REFERENCES}

CASTLE, W. E. 1921. An improved method of estimating the number of genetic factors concerned in cases of blending inheritance. Science, 54, 223.
FINNEY, D. J. 1971. Probit analysis, Cambridge University Press, Cambridge.

GEORGHIOU, G. P., METCALF, R. L. AND GIDDEN, F. E. 1966. Carbamate resistance in mosquitoes. Bull. WHO, 35, 691708.

GUPTAVANiJ, P. AND BARR, A. R. 1979. Plum-eye, a marker for the third linkage group in Culex pipiens (Diptera: Culicidae). J. Med. Entomol., 16, 219-222.

LANDE, R. 1981. The number of genes contributing to quantitative variation between and within populations. Genetics, 99, 541-553.

MISRA, R. K. 1968. Statistical tests of hypothesis concerning the degree of dominance in monofactorial inheritance. Biometrics, 24, 429-434.

PASTEUR, N. 1977. Recherche de génétique chez Culex pipiens L. Polymorphisme Enzymatique, Autogénèse et Résistance aux insecticides organophosphorés. Thèse de Doctorat d'Etat, Université de Montpellier II, Montpellier, France.

PASTEUR, N., ISEKI, A. AND GEORGHIOU, G. P. 1981. Genetic and biochemical studies of the highly active esterases $A^{\prime}$ and $B$ associated with organosphosphate resistance in mosquitoes of the Culex pipiens complex. Biochem. Genet., 19, 909-919.

PASTEUR, N. AND SINÈGRE, G. 1978. Chlorpyrifos (Dursban) resistance in Culex pipiens pipiens $\mathrm{L}$. from southern France: inheritance and linkage. Experientia, 34, 709-710.

PASTEUR, N., SiNÈGRE, G. AND GABINAUd, A. 1981. Est-2 and Est-3 polymorphism in Culex pipiens from Southern France in relation to organophosphate resistance. Biochem. Genet., 19, 499-508.

RAYMOND, M. 1985. Présentation d'un programme d'analyse log-probit pour micro-ordinateur. Cah. O.R.S.T.O.M., sér. Ent. méd. et Parasitol, 22, 117-121.

RAYMOND, M., FOURNIER, D., BERGÉ, J., CUANY, A., BRIDE, J. M. AND PASTEUR, N. 1985a. Single-mosquito test to determine genotypes with an acetylcholinesterase insensitive to inhibition to propoxur insecticide. J. Am. Mosq. Control Assoc., 1, 425-427.

RAYMOND, M., GAVEN, B., PASTEUR, N. AND SINEGRE, G. $1985 \mathrm{~b}$. Etude de la résistance au chlorpyrifos à partir de quelques souches du moustique Culex pipiens L. du sud de la France. Génét. Sélect. Evol., 17, 73-88.

RAYMOND, M., PASTEUR, N., FOURNIER, D., CUANY, M., BERGE, J. AND MAGNIN, M. 1985c. Le gène d'une acétylcholinestérase insensible au propoxur détermine la résistance de Culex pipiens à cet insecticide. C.R. Acad. Sc., III, 300, 509-512.

RAYMOND, M., PASTEUR, N., FOURNIER, D., BRIDE, J, M., CUANY, A., BERGÉ, J. AND MAGNIN, M. 1986. Identification of resistance mechanisms in Culex pipiens (Diptera: Culicidae) from southern France: insensitive acetylcholinesterase and detoxifying esterases. J. Econ. Entomol., 79, 1452-1458.

SOKAL, R. AND ROHLF, F. J. 1981. Biometry, W. H. Freeman and Co., New York.

SINÈGRE, G., JULLIEN, J. L. AND CRESPO, O. 1976. Résistance de certaines populations de Culex pipiens (L.) au chlorpyrifos (Dursban) en Languedoc-Roussillon (France). Cahier O.R.S.T.O.M., Ser. Entomol. méd et Parasitol., 14, 49-59.

STONE, B. F. 1968. A formula for determining degree of dominance in cases of monofactorial inheritance of resistance to chemicals. Bull. WHO, 38, 325-326. 